\title{
A refined experimental model of fusiform aneurysms in a rabbit carotid artery
}

\author{
Michael B. Avery, MD, MSc, ${ }^{1,2}$ Ahmed Alaqeel, MD, MBA, ${ }^{1}$ Amy B. Bromley, MD, ${ }^{3}$ \\ Yong-Xiang Chen, MD, PhD, ${ }^{4}$ John H. Wong, MD, MSc, ${ }^{1,5,6}$ Muneer Eesa, MD, ${ }^{1,5}$ and \\ Alim P. Mitha, MD, SM1,5,6

\begin{abstract}
1Department of Neurosciences, ${ }^{2}$ Neuroscience Graduate Program, ${ }^{3}$ Department of Pathology \& Laboratory Medicine, ${ }^{4}$ Libin Cardiovascular Institute of Alberta, ${ }^{5}$ Department of Radiology, and ${ }^{6}$ Hotchkiss Brain Institute, University of Calgary,
\end{abstract} \\ Alberta, Canada
}

OBJECTIVE Reliable animal models are an important aspect of translational research, especially for relatively uncommon clinical entities such as fusiform aneurysms. While several animal models exist, very few are tailored to cerebral fusiform aneurysms, which have unique attributes compared to abdominal fusiform aneurysms. The authors aimed to build from previous models to create a cerebral fusiform aneurysm model that is simple to use and reliable.

METHODS Twelve female New Zealand White rabbits were assigned to 3 groups: group E, elastase only; group C, $\mathrm{CaCl}_{2}$ only; group $\mathrm{EC}$, elastase $+\mathrm{CaCl}_{2}$. All rabbits underwent surgical exposure of the right common carotid artery (CCA) and 20 minutes of peri-carotid incubation with their respective chemicals. Angiography was performed 6 weeks later for arterial dilation measurements, with $50 \%$ increase in diameter being defined as fusiform aneurysm formation. The arterial segments, along with the contralateral CCAs, were harvested and assessed histologically for wall component measurements and elastin semiquantification. A separate rabbit underwent aneurysm creation per the group EC protocol and was treated with an endovascular flow-diversion device.

RESULTS All of the group EC rabbits developed fusiform aneurysms (mean dilation of $88 \%$ ), while none of the group $E$ or group $C$ rabbits developed aneurysms $(p=0.001)$. Histological analysis revealed increased internal elastic lamina fragmentation in the group EC aneurysms, which also had less tunica intima hyperplasia. All aneurysms exhibited thinning of the tunica media and reduction in elastin content. The use of an endovascular flow-diverting stent was successful, with complete parent vessel remodeling, as expected, 4 weeks after deployment.

CONCLUSIONS The peri-arterial application of combined elastase and $\mathrm{CaCl}_{2}$ to the $\mathrm{CCA}$ appears sufficient to reliably produce fusiform aneurysms after 6 weeks. Exposure to elastase or $\mathrm{CaCl}_{2}$ individually appears insufficient, despite the observed histological changes to the arterial wall. The proposed fusiform aneurysm model is able to accommodate endovascular devices, simulating the tortuous pathway experienced in using such devices in human cerebral aneurysms and thus is a satisfactory model to use in translational research.

https://thejns.org/doi/abs/10.3171/2018.2.JNS173168

KEYWORDS fusiform aneurysm; elastase; calcium chloride; animal model; vascular disorders

I NTRACRANIAL aneurysms are pathological dilations of a cerebral blood vessel and can occur anywhere throughout the vascular tree. Saccular morphologies are by far the most common, with nonsaccular morphologies being quite rare in comparison. ${ }^{3}$ The nonsaccular subgroup includes fusiform, dolichoectatic, and dissecting aneurysms-lesions that are found at nonbranching arte- rial segments. Fusiform aneurysms are defined as having a circumferential dilation of at least 1.5 times the baseline vessel diameter and are thought to represent less than $15 \%$ of intracranial aneurysms. ${ }^{10,11}$ Histologically, they differ from saccular aneurysms as they are the result of circumferential dilation of the arterial wall, as opposed to focal outpouching. They also share similar features in that they

ABBREVIATIONS BAPN = 3-aminopropionitrile fumarate salt; CCA = common carotid artery; $\mathrm{SC}=$ subcutaneously; VVG = Verhoeff-Van Gieson. SUBMITTED December 23, 2017. ACCEPTED February 22, 2018.

INCLUDE WHEN CITING Published online July 27, 2018; DOI: 10.3171/2018.2.JNS173168. 
exhibit loss of the internal elastic lamina with a degraded tunica media and tunica intima hyperplasia. ${ }^{5,16}$

Despite their relatively low prevalence, fusiform aneurysms are clinically very important, as they are notoriously difficult to treat. Furthermore, their exact pathogenesis remains elusive. Therefore, it is important to develop reliable and reproducible animal models of these aneurysms for the purpose of translational research into both their pathogenesis and their treatment. While several fusiform animal models have been developed, they are not optimized for studying intracranial aneurysms. Some issues include relatively low reproducibility, technically challenging models, and lack of proximal vasculature tortuosity to mimic the endovascular access of the cerebral arterial system. Having a model that addresses these shortcomings will not only improve our collective ability to study fusiform aneurysms but also improve the translatability of such investigations. Building off previously described models, we developed a novel model of fusiform aneurysms in the rabbit common carotid artery (CCA) that addresses these issues.

\section{Methods}

All methodology was performed in accordance with the ethics certification received from our institution's animal care committee. Twelve female New Zealand White rabbits (Charles River Laboratories International), each approximately 13 weeks of age with weight between 2-3 $\mathrm{kg}$, were used in the primary part of this study. The rabbits were housed in our animal care facility with a 12hour light/dark cycle and access to food and water ad libitum.

\section{Fusiform Aneurysm Creation}

Each rabbit underwent the surgical procedures for creation of a right CCA fusiform aneurysm after being randomly assigned to one of 3 groups: elastase only (group $\mathrm{E}, \mathrm{n}=3$ ), $\mathrm{CaCl}_{2}$ only (group $\mathrm{C}, \mathrm{n}=3$ ), and elastase plus $\mathrm{CaCl}_{2}$ (group $\mathrm{EC}, \mathrm{n}=6$ ). For all procedures, rabbits were first given a dose of an antibiotic agent (enrofloxacin [Baytril], $10 \mathrm{mg} / \mathrm{kg}$, administered subcutaneously [SC]). Then anesthesia was induced with acepromazine $0.3 \mathrm{mg} / \mathrm{kg}$, administered intravenously, and the animals were intubated and maintained on $100 \% \mathrm{O}_{2}$ at $1 \mathrm{~L} /$ minute with isoflurane $5 \%$. Ketoprofen (Anafen) $1 \mathrm{mg} / \mathrm{kg} \mathrm{SC}$ and buprenorphine $0.03 \mathrm{mg} / \mathrm{kg} \mathrm{SC}$ were administered for analgesia. The ventral neck was shaved and prepared with povidone-iodine, then draped in a sterile fashion. A 3-cm midline longitudinal incision was made, and the right carotid sheath was identified after dissecting down the medial border of the right sternocleidomastoid muscle. The sheath was opened and a $2.5-\mathrm{cm}$ segment of the right CCA was identified and isolated. A $2 \mathrm{~cm} \times 2 \mathrm{~cm}$ piece of sterile gauze was carefully wrapped around a $2-\mathrm{cm}$ segment of the CCA. A 2-cm-long cradle was created by cutting a narrow longitudinal strip out of a sterilized standard drinking straw. The cradle was then placed around the gauze-wrapped CCA, isolating the artery from the surrounding tissues. Based on group allocation, the gauze was then soaked in $1 \mathrm{~mL}$ of fluid consisting of $0.5 \mathrm{~mL}$ of elastase (75 units) and $0.5 \mathrm{~mL}$ of phosphate-buffered saline (PBS) (group E), or $0.5 \mathrm{~mL}$ of $\mathrm{CaCl}_{2}(0.5 \mathrm{M})$ and $0.5 \mathrm{~mL}$ of PBS (group C), or $0.5 \mathrm{~mL}$ of elastase (75 units) and $0.5 \mathrm{~mL}$ of $\mathrm{CaCl}_{2}(0.5 \mathrm{M})$ (group EC). CCAs were bathed in their respective solutions for 20 minutes. Then the cradle was removed and the tissue was washed thoroughly with normal saline. The incision was closed in layers with Vicryl sutures and the rabbits were awoken. Postoperatively, the rabbits were given enrofloxacin $10 \mathrm{mg} / \mathrm{kg}$ orally daily for 3 days and buprenorphine $0.03 \mathrm{mg} / \mathrm{kg}$ SC every 12 hours for 36 hours.

\section{Digital Subtraction Angiography}

Angiography was performed at 6 weeks in all rabbits to assess the developing fusiform aneurysm. Rabbits were anesthetized as above, and the right groin region was shaved. A surgical cut-down to the right femoral artery was performed and a Prelude 4-Fr introducer sheath (Merit Medical) was inserted through an arteriotomy. Under fluoroscopic guidance, an Impress 4-Fr guide catheter (Merit Medical) over a 0.035-inch Glidewire guidewire (Terumo Corporation) was passed retrograde through the descending aorta and into the brachiocephalic artery. The catheter was parked at the origin of the right CCA, and both anteroposterior and right anterior oblique fluoroscopic images were acquired by rapidly injecting nonionic iodinated low-osmolar contrast medium. A coin measuring $18 \mathrm{~mm}$ in diameter was placed in the imaging field for reference to control for distance between the rabbit and detector. Dilated right CCA diameter was recorded as the greatest transverse dimension, measured perpendicular to the artery. The baseline diameter was defined as the maximum arterial dimension proximal to the dilated segment at the origin of the CCA, measured perpendicular to the long axis. Diameter increase was calculated as follows: ([dilated artery diameter - baseline diameter]/baseline diameter) $\times 100 \%$.

\section{Histological Analyses}

Immediately after angiography, the rabbits were killed; they were deeply sedated with $5 \%$ inhaled isoflurane, and then $4 \mathrm{~mL}$ of $10 \%$ buffered formalin was injected into the heart in accordance with ethical standards. Both CCAs from 2 randomly selected rabbits from each group were then surgically harvested and placed in $10 \%$ buffered formalin for at least 5 days prior to serial alcohol dehydration and paraffin embedding. Blocks were sectioned with 5- $\mu \mathrm{m}$ thicknesses and stained with Verhoeff-Van Gieson (VVG) stain. Slides were scanned using Aperio whole slide imaging (Leica Biosystems Pathology Imaging) and were studied by an experienced histopathologist. Specifically, tunica media and tunica intima thicknesses were recorded, as well as tunica media elastin semiquantification, for both CCAs from each rabbit. Elastin semiquantification analysis was performed on representative sections of each artery by measuring the elastin content in the VVGstained sections using a colorimetric analysis algorithm with Aperio ImageScope software version 12.3.0.5056 (Leica Biosystems Pathology Imaging). Elastin semiquantification was expressed as ratio of black pixels (representing elastin fibers) to nonblack pixels within the selected tissue regions. 
TABLE 1. Comparison of angiographic measurements of right CCAs at baseline and 6 weeks after exposure to elastase, $\mathrm{CaCl}_{2}$, or the combination of elastase and $\mathrm{CaCl}_{2}$

\begin{tabular}{cccc}
\hline Group \& Rabbit No. & $\begin{array}{c}\text { Baseline CCA } \\
\text { Diameter }(\mathrm{mm})\end{array}$ & $\begin{array}{c}\text { Dilated CCA } \\
\text { Diameter }(\mathrm{mm})\end{array}$ & $\begin{array}{c}\text { Diameter } \\
\text { Increase }(\%)\end{array}$ \\
\hline $\begin{array}{c}\text { Group E (elastase } \\
\text { only) }\end{array}$ & & & \\
\hline 1 & 2 & 2.4 & 20 \\
\hline 2 & 2.4 & 2.9 & 20.8 \\
\hline 3 & 2.4 & 2.5 & 4.2 \\
\hline Mean (SD) & $2.3(0.23)$ & $2.6(0.26)$ & $15(9.36)$ \\
\hline $\begin{array}{c}\text { Group C (CaCl }{ }_{2} \\
\text { only) }\end{array}$ & & & \\
\hline 4 & 2 & 2 & 0 \\
\hline 5 & 2.2 & 2 & -9.1 \\
\hline 6 & 1.8 & 2.1 & 16.7 \\
\hline Mean (SD) & $2(0.2)$ & $2(0.06)$ & $2.5(13.09)$ \\
\hline $\begin{array}{c}\text { Group EC (elastase } \\
+ \text { CaCl })\end{array}$ & & & \\
\hline 7 & 2.1 & 4.2 & 100 \\
\hline 8 & 2.1 & 4.1 & 95.2 \\
\hline 9 & 2 & 3.9 & 95 \\
\hline 10 & 1.8 & 3.4 & 88.9 \\
\hline 11 & 1.7 & 3.3 & 94.1 \\
\hline 12 & 2.2 & 3.4 & 54.5 \\
\hline Mean (SD) & $2(0.19)$ & $3.7(0.4)$ & $88(16.76)$ \\
\hline
\end{tabular}

Aneurysm formation was defined as a diameter increase of at least $50 \%$.

\section{Statistical Analyses}

Arterial diameter increase after treatment was compared between the 3 groups using the Kruskal-Wallis exact test with $\alpha$ set at 0.05 . A nonparametric test was selected because the data were not normally distributed. Post hoc testing was performed using the Mann-Whitney U-test with a Bonferroni correction.

\section{Endovascular Device Testing}

A right CCA fusiform aneurysm was created as above in a 13th rabbit, separate from the study, for the purpose of testing the ability to use endovascular devices in the model. This rabbit was handled identically in our animal housing facility with regards to light/dark cycle and access to food and water. During week 5 after aneurysm creation, the rabbit was administered aspirin $(10 \mathrm{mg} / \mathrm{kg})$ and clopidogrel $(10 \mathrm{mg} / \mathrm{kg})$ daily. At 6 weeks after aneurysm creation, angiography was performed as described above. Subsequently, a Marksman 27 catheter (Medtronic) was guided across the aneurysm. Two overlapping Pipeline embolization devices (Covidien Ltd.), measuring 2.5 $\mathrm{mm} \times 20 \mathrm{~mm}$ and $2.5 \mathrm{~mm} \times 16 \mathrm{~mm}$, were deployed across the span of the aneurysm. The animal was allowed to recover, and treatment with aspirin and clopidogrel was continued. At 10 weeks after aneurysm creation another angiographic study was performed to assess the patency of the Pipeline embolization devices. The rabbit was

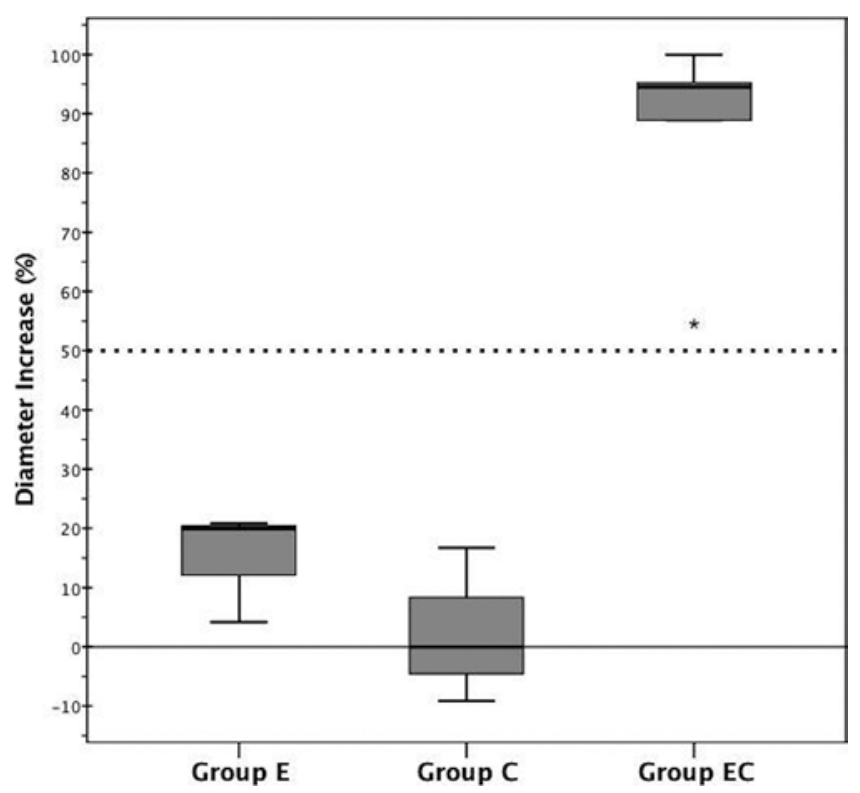

FIG. 1. Box plot of right CCA diameter increases as measured on angiography 6 weeks after aneurysm creation showing median and interquartile values with outliers $\left(^{*}\right)$. See Methods for diameter increase formula. Aneurysm formation was defined as at least a $50 \%$ diameter increase (dashed line). Group $\mathrm{E}=$ elastase only; Group $\mathrm{C}=\mathrm{CaCl}_{2}$ only; Group EC = elastase $+\mathrm{CaCl}_{2}$.

killed post-angiography in the same manner as the other 12 study rabbits.

\section{Results}

All 12 rabbits in the E, C, and EC groups were included in the study, and there were no perioperative or angiography-associated complications. Per the aneurysm definition established a priori, none of the group E or group C rabbits formed fusiform aneurysms, while all 6 group EC rabbits formed fusiform aneurysms (Table 1 and Fig. 1). The mean diameter increase was 15\% (SD 9.36\%), 2.5\% (SD 13.09\%) and 88\% (SD 16.76\%), respectively, which reached statistical significance $\left(\chi^{2}=8.396, p=0.001\right)$. Post hoc testing revealed group EC being significantly larger than groups $\mathrm{E}$ and $\mathrm{C}$ (groups $\mathrm{E}, \mathrm{C}$ : $\mathrm{U}=1, \mathrm{p}=0.1$; groups $\mathrm{E}, \mathrm{EC}: \mathrm{U}=0, \mathrm{p}=0.012$; groups $\mathrm{C}, \mathrm{EC}: \mathrm{U}=0, \mathrm{p}=0.012$ ).

The 2 group E right CCAs analyzed histologically demonstrated a thinning of the tunica media and thickening of the tunic intima compared to their respective internal control CCAs. A similar finding was noted in the 2 group $\mathrm{C}$ right CCAs analyzed, except with a more pronounced degree of tunica intima hyperplasia. There was also marked calcium deposition in the tunicae mediae. While both of the group EC right CCAs that were analyzed also displayed marked thinning of the tunica media, the degree of tunica intima hyperplasia was less than that seen in the other groups (Table 2). All arteries from all groups demonstrated internal elastic lamina fragmentation. However, the degree of fragmentation appeared to be much greater in the group EC arteries. With regards to elastin semiquantification, all right CCAs demonstrated loss of 
TABLE 2. Tunica media and tunica intima thicknesses of 2 representative right CCAs from each group compared with their respective contralateral normal CCAs (internal control)

\begin{tabular}{|c|c|c|c|c|c|c|}
\hline \multirow[b]{2}{*}{ Group } & \multicolumn{6}{|c|}{ Thickness $(\mu \mathrm{m})$} \\
\hline & Rt CCA Tunica Media & Control Tunica Media & Diff in Tunica Media & Rt CCA Tunica Intima & Control Tunica Intima & Diff in Tunica Intima \\
\hline \multirow{2}{*}{ Group E } & 70.4 & 92.6 & -22.2 & 34.1 & 4.7 & 29.4 \\
\hline & 69.5 & 101.5 & -32 & 32.2 & 3.4 & 28.8 \\
\hline \multirow{2}{*}{ Group C } & 57.3 & 89.4 & -32.1 & 91.8 & 7.4 & 84.4 \\
\hline & 93.7 & 109.4 & -15.7 & 78.4 & 2.5 & 75.9 \\
\hline \multirow{2}{*}{ Group EC } & 100.2 & 123.6 & -23.4 & 80.6 & 2.6 & 78 \\
\hline & 11.9 & 94.4 & -82.5 & 18.6 & 4.5 & 14.1 \\
\hline
\end{tabular}

Diff $=$ difference

Differences were calculated as right CCA measurement minus internal control measurement.

elastin content in the tunica media, with the exception of 1 group EC right CCA, which had an absolute increase in relative tunica media elastin content of $7 \%$ compared to the internal control artery (Table 3). This same experimental artery demonstrated a strikingly large degree of tunica media loss compared to the other group EC right CCA (Fig. 2).

The rabbit that underwent right CCA fusiform aneurysm creation for testing an endovascular device had an aneurysm with diameter increase of $87 \%$ at 6 weeks after creation. Two Pipeline embolization devices were successfully deployed across the aneurysm with no complications noted (Fig. 3). The rabbit awoke in good condition and was monitored for the subsequent 4 weeks. No complications were noted during this time. A follow-up angiogram was performed which demonstrated complete remodeling of the parent vessel without any obvious residual aneurysm.

\section{Discussion}

In this study, we present a new fusiform aneurysm model for the rabbit CCA using a combination of topical elastase and $\mathrm{CaCl}_{2}$. Previous studies have shown that the application of calcium to an arterial wall results in its deposition within, and subsequent destruction of, the internal elastic lamina and elastic fibers of the tunica media, medi-

TABLE 3. Right CCA wall elastin semiquantification in 2 representative dilated arteries from each group compared with their respective contralateral normal CCA (internal control)

\begin{tabular}{cccc}
\hline \multirow{2}{*}{ Group } & \multicolumn{3}{c}{ Semiquantification (\%) } \\
\cline { 2 - 4 } & $\begin{array}{c}\text { Rt CCA Wall } \\
\text { Elastin }\end{array}$ & $\begin{array}{c}\text { Control Wall } \\
\text { Elastin }\end{array}$ & $\begin{array}{c}\text { Absolute Diff in Wall } \\
\text { Elastin }\end{array}$ \\
\hline \multirow{2}{*}{ Group E } & 75.7 & 66.7 & 9 \\
\cline { 2 - 4 } & 22.5 & 52.9 & -30.4 \\
\hline \multirow{2}{*}{ Group C } & 12.5 & 62.8 & -50.3 \\
\cline { 2 - 4 } & 58.4 & 59.9 & -1.5 \\
\hline \multirow{2}{*}{ Group EC } & 14 & 44.4 & -30.4 \\
\cline { 2 - 4 } & 68.6 & 61.6 & 7 \\
\hline
\end{tabular}

Absolute difference was calculated as right CCA wall percentage minus control wall percentage. ated by the affinity of calcium for elastin. ${ }^{12}$ The summative effect of elastase and $\mathrm{CaCl}_{2}$, when applied to the surface of the CCA, is increased aneurysm formation when compared to the result of application of each component individually, as observed in our model. Activation of an elastolytic cascade in this model imitates a major component of the pathogenesis of human fusiform aneurysms. ${ }^{7,19}$

On histological analysis, we observed several important findings. The primary outcome was the diameter increase seen in the exposed arterial segments. We found that periarterial incubation with the combination of elastase and $\mathrm{CaCl}_{2}$ resulted in fusiform aneurysm formation, but incubation with elastase or $\mathrm{CaCl}_{2}$ individually did not. Next, the internal elastic lamina was largely absent in the group $\mathrm{EC}$ arteries, with some persistence in group $\mathrm{C}$ and group $\mathrm{E}$ arteries. Knowing that calcium's affinity for elastin leads to destruction of elastin suggests that the external application of elastase alone is insufficient for significant internal elastic lamina degradation. This also suggests that elastase and $\mathrm{CaCl}_{2}$ work synergistically to degrade the internal elastic lamina. Incomplete penetrance through the tunica adventitia and tunica media of each of these substances may contribute to their individual failure to degrade the internal elastic lamina. No models have been described using only peri-arterial elastase, while the models of Anidjar et al., ${ }^{2}$ Tanaka et al. ${ }^{19}$ Fahed et al. ${ }^{9}$ and $\mathrm{Hu}$ et al. ${ }^{13}$ have used intra-arterial elastase with success, representing a shorter tissue penetration distance. Tian and colleagues utilized intra-adventitial injections of elastase only in a pig thoracic aorta and achieved fusiform aneurysm formation. ${ }^{20}$ However, the incubation time was indefinite in their model, as opposed to our 20-minute incubation time followed by washout, perhaps explaining the efficacy of elastase in their model.

Our model also demonstrated a reduction in tunica media thickness and simultaneous thickening of the tunica intima in all groups. Interestingly, the group EC aneurysm with the largest degree of tunica media degeneration $(-82.5 \mu \mathrm{m})$ was the aneurysm that demonstrated the smallest degree of dilation (54.5\%), smallest degree of tunica intima thickening (14.1 $\mu \mathrm{m})$, and a slight increase in elastin semiquantification (increase of $7 \%$ ). Elastin content is a relative measure representing a proportion of the tissue analyzed that stains for elastin fibers. 


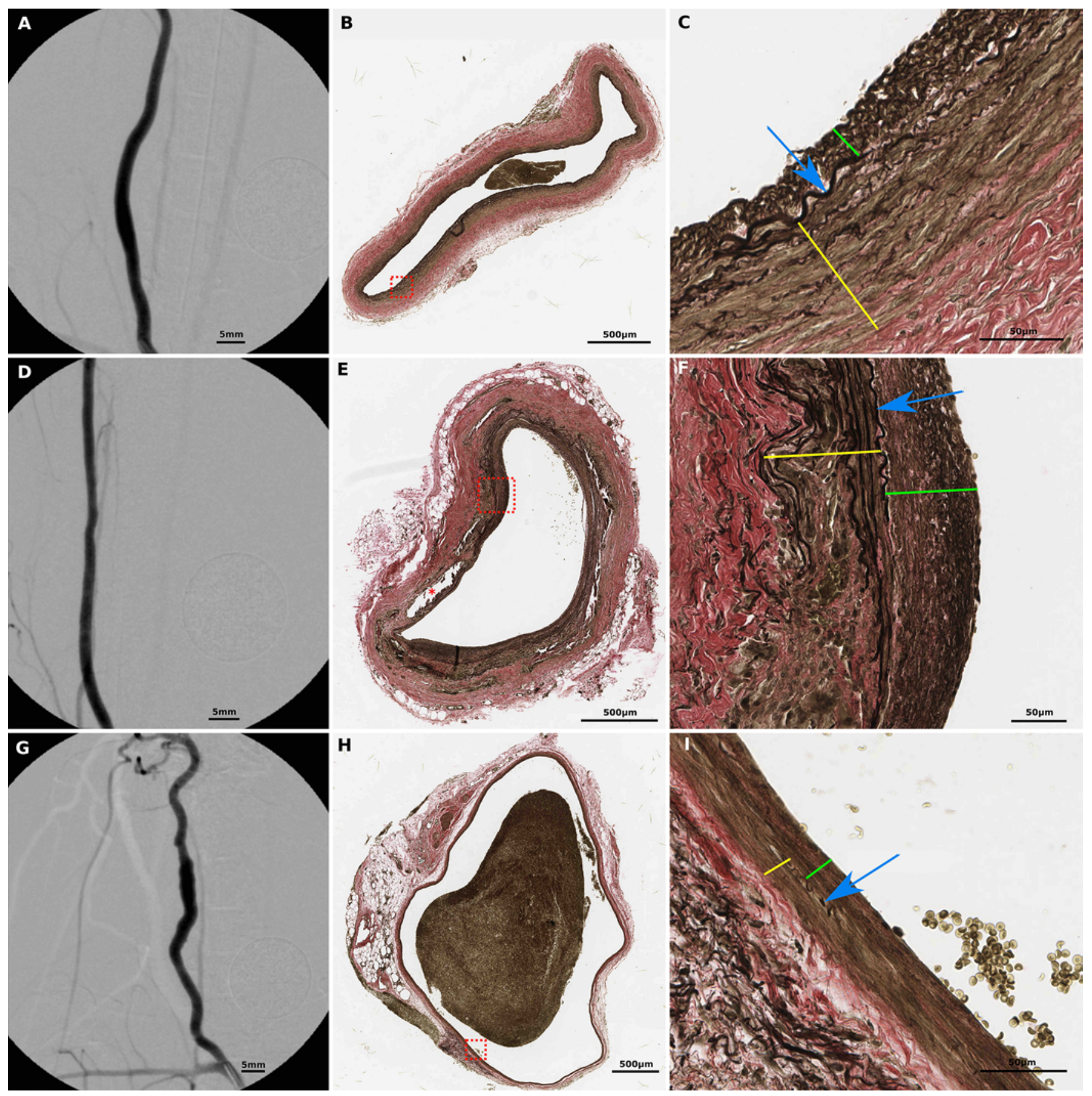

FIG. 2. A: Anteroposterior angiographic projection of a right CCA obtained after peri-arterial exposure to $0.5 \mathrm{~mL}$ of elastase (75 units) and $0.5 \mathrm{~mL}$ of PBS (group E). The catheter is lying proximal to the exposed arterial segment. Mild dilation was noted compared to baseline, but no fusiform aneurysm was formed. B: Histological cross-section of a group E artery with a small amount of acute thrombus in the lumen formed during harvest. The red dashed box indicates the section of wall magnified in panel $\mathrm{C}$. C: Magnified portion of wall of a group E artery showing mild fragmentation of internal elastic lamina (blue arrow) with thickened tunica intima (green line) and mildly thinned tunica media (yellow line). D: Anteroposterior angiographic projection of a right CCA after peri-arterial exposure to $0.5 \mathrm{~mL}$ of $0.5-\mathrm{M} \mathrm{CaCl}_{2}$ and $0.5 \mathrm{~mL}$ of PBS (group C). No dilation or aneurysm formation was noted. E: Histological cross-section of a group $\mathrm{C}$ artery with several areas of calcification within the tunica media (example marked with red asterisk). The red dashed box indicates the section of wall magnified in panel F. F: Magnified portion of wall of a group C artery showing mild fragmentation of internal elastic lamina (blue arrow) with thickened tunica intima (green line) and mildly thinned tunica media (yellow bar). G: Anteroposterior angiographic projection of a right CCA fusiform aneurysm induced by peri-arterial application of $0.5 \mathrm{~mL}$ of elastase $\left(75 \mathrm{U}\right.$ ) and $0.5 \mathrm{~mL}$ of $0.5-\mathrm{M} \mathrm{CaCl}_{2}$ (group EC). $\mathrm{H}$ : Histological cross-section of a group EC fusiform aneurysm showing acute thrombus in the lumen formed during aneurysm harvest. The red dashed box indicates the section of wall magnified in panel I. I: Magnified portion of wall of group EC fusiform aneurysm showing highly fragmented internal elastic lamina (blue arrow) with thickened tunica intima (green bar) and significantly thinned tunica media with sparse elastic fiber content (yellow bar). All histological sections were stained with VVG stain to highlight elastic fibers in black. Figure is available in color online only. 


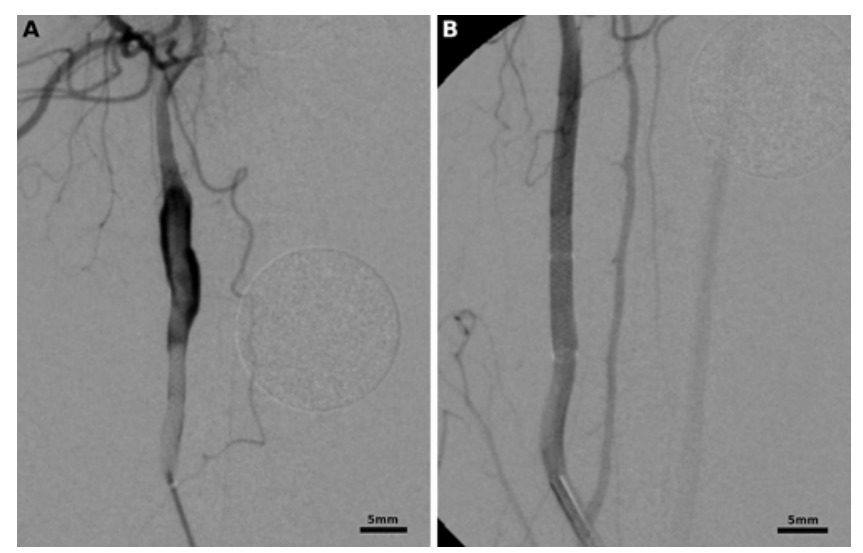

FIG. 3. A: Anteroposterior angiographic projection of right CCA fusiform aneurysm obtained 6 weeks after creation (peri-arterial application of $0.5 \mathrm{~mL}$ of elastase [75 U] and $0.5 \mathrm{~mL}$ of $0.5-\mathrm{M} \mathrm{CaCl}_{2}$ ) and immediately after 2 Pipeline embolization devices $(2.5 \mathrm{~mm} \times 20 \mathrm{~mm}$ and $2.5 \mathrm{~mm} \times$ $16 \mathrm{~mm}$ ) were deployed across the length of the aneurysm. B: Anteroposterior angiographic projection of the same right CCA fusiform aneurysm 4 weeks later showing complete remodeling of the parent vessel.

As the absolute thickness of the tunica media was very small, an increase in percentage of semiquantified elastin compared to the internal control CCA does not represent an absolute increase in the elastin content, which we are unable to quantify. A greater amount of preserved tunica adventitia may be responsible for minimizing dilation. As mentioned, all groups demonstrated tunica media degeneration and tunica intima hyperplasia compared to internal control arteries, yet fusiform aneurysm formation was not observed in group $\mathrm{E}$ and group $\mathrm{C}$ arteries. This indicates that fusiform aneurysm formation is not simply based on tunica media and internal elastic lamina degradation with reactive tunica intima hyperplasia. Instead, there is likely a highly complicated interplay of inflammatory mediators and moderators not quantified in this study.,5,15,16,20

Most fusiform aneurysm animal models utilize the abdominal aorta due to its easy surgical access, providing a long arterial segment with a relatively large diameter in small rodent species (Table 4). In addition to our model, the only other model that used exclusively the CCA was the rabbit model of Gertz et al. ${ }^{12}$ Their model involved the peri-carotid application of $0.5-\mathrm{M} \mathrm{CaCl}_{2}$ with no elastase. They demonstrated a $60 \%$ increase in lumen diameter on angiography at 3 weeks compared to baseline diameters measured distal on the same CCA. Their success rate was $75 \%$. While we found a mean diameter increase of only $2.5 \%$ for group $\mathrm{C}$ rabbits, we compared the aneurysmal segments' diameters to the proximal vessel diameter, which may account for the smaller calculated effect size. Our histological analyses demonstrated a reduction in tunica media thickness with increased tunica intima thickness, indicating that the $\mathrm{CaCl}_{2}$ certainly had an effect on the arterial walls in our study as well. Using a combination of elastase and $\mathrm{CaCl}_{2}$, we observed a larger increase in diameter than reported by Gertz et al., despite using a more conservative measurement methodology, with greater reliability at 4 weeks. Hu et al. used a rat aorta model with intra-aortic elastase incubation for 30 minutes and indi- rectly reported an arterial dilation ratio greater than $200 \%$ at 4 weeks. ${ }^{13}$ However, they calculated their dilation ratio as a ratio between the aneurysm maximum diameter and the aortic baseline diameter, giving much higher values for a given amount of dilation than the formula used in our study. A $200 \%$ dilation ratio in their study would correspond to a $100 \%$ increase in our study, indicating similar results. Lu et al. bathed mouse aortae with elastase while adding 3-aminopropionitrile fumarate salt (BAPN) to the animals' drinking water and found a mean aortic dilation of $285.8 \%$ at 4 weeks, using the same formula as we used in our study. ${ }^{15}$ However, the continuous exposure of BAPN throughout the observational period led to progressive increases in aneurysm size over 100 days with an associated increasing rupture rate. We observed no aneurysm ruptures in our study, demonstrating the stability and reliability of our model.

A rabbit was chosen for this fusiform CCA model as the species has several important advantages allowing for human translational studies. New Zealand White rabbits are cost-effective as they are inexpensive to purchase and house, allowing for many animals to be included in studies. Aneurysms created in rabbits have been shown to be similar to those found in humans, including degradation of the tunica media and internal elastic lamina as well as hyperplasia of the tunica intima, all of which were also found in the current model., ${ }^{1,5}$ While not demonstrated in this study, aneurysms formed using elastase in rabbits are stable over many months to years with no significant spontaneous thrombosis. ${ }^{1,8}$ In other animal models, such as pigs, rheological properties differ, leading to increased coagulability and spontaneous aneurysm thrombosis. ${ }^{6,17} \mathrm{Fi}-$ nally, the location of the rabbit CCA fusiform aneurysm is such that endovascular access requires navigating a more tortuous path compared to aortic models, similar to many cerebral aneurysm locations in the human. As demonstrated in this study, navigating and deploying relatively stiff devices, such as the Pipeline embolization device, at the aneurysm site is still feasible in this model, and the 4-week follow-up angiogram demonstrated the expected remodeling of the aneurysmal vessel. Therefore, we believe that this model may be used to test novel endovascular devices for potential use in humans. That being said, the morphology of the proximal CCA is relatively simple, with no branches to be incorporated into the aneurysm, rendering the hemodynamics quite simple as well. Human fusiform aneurysms do not always involve arteries of this configuration, and thus hemodynamics are often more complex than represented in our model. This may be seen as a limitation of the current model. The model published by Fahed et al. utilized a segment of the subclavian artery with its branches, representing a more complex arterial configuration that may mimic human fusiform aneurysms in general more closely. ${ }^{9}$ It would be of interest to use our model either further distal at the level of the CCA bifurcation, or in another artery with branches. This would require the fabrication of a custom arterial cradle that conforms to the particular morphology of the artery of interest.

Our model builds upon that proposed by $\mathrm{Bi}$ et al. for the abdominal aortic aneurysm, using a 20-minute periarterial incubation with elastase and $\mathrm{CaCl}_{2}$, yet it has sev- 
TABLE 4. Comparison of our new fusiform aneurysm model with previous similar fusiform aneurysm animal models

\begin{tabular}{|c|c|c|c|c|c|c|}
\hline Model & $\begin{array}{l}\text { Animal \& } \\
\text { Vessel }\end{array}$ & Description & $\begin{array}{l}\text { Chemical } \\
\text { Exposure } \\
\text { Time }\end{array}$ & $\begin{array}{l}\text { Success } \\
\text { Rate }\end{array}$ & $\begin{array}{c}\text { Mean } \\
\text { Diameter } \\
\text { Increase }(\%)\end{array}$ & Limitations \\
\hline $\begin{array}{l}\text { Gertz et al., } \\
1988\end{array}$ & Rabbit CCA & Bathed artery in $0.5-\mathrm{M} \mathrm{CaCl}_{2}$ & 15 mins & $\begin{array}{c}75 \% \text { at } 3 \\
\text { wks }\end{array}$ & $\begin{array}{c}60 \% \text { at } 3 \\
\text { wks }\end{array}$ & Moderate success rate \\
\hline $\begin{array}{l}\text { Anidjar et } \\
\text { al., } 1990\end{array}$ & Rat aorta & $\begin{array}{l}\text { Intra-aortic elastase ( } 15 \mathrm{U} \text { ) via femoral } \\
\text { catheter; simultaneous surgical expo- } \\
\text { sure of aorta }\end{array}$ & $2 \mathrm{hrs}$ & $\begin{array}{l}100 \% \text { (of } \\
\text { survivors) } \\
\text { at } 3 \text { wks }\end{array}$ & NR & $\begin{array}{l}\text { Long incubation period; high } \\
\text { mortality rate; ligation of all } \\
\text { aortic segmental branches }\end{array}$ \\
\hline $\begin{array}{l}\text { Isenburg et } \\
\text { al., } 2007\end{array}$ & Rat aorta & Peri-aortic $0.5-\mathrm{M} \mathrm{CaCl}_{2}$ & 15 mins & $\begin{array}{l}66.7 \% \text { at } 4 \\
\text { wks }\end{array}$ & $\begin{array}{c}42 \% \text { at } 4 \\
\text { wks }\end{array}$ & $\begin{array}{l}\text { Ltd artery dilation; relatively } \\
\text { low success rate }\end{array}$ \\
\hline $\begin{array}{l}\text { Tanaka et } \\
\text { al., } 2009\end{array}$ & Rat aorta & $\begin{array}{l}\text { Intra-aortic elastase (30 U) \& peri-aortic } \\
\quad 0.5-\mathrm{M} \mathrm{CaCl}_{2}\end{array}$ & 20 mins & $\begin{array}{l}92.7 \% \text { at } 4 \\
\text { wks }\end{array}$ & $\begin{array}{l}94.8 \% \text { at } 4 \\
\text { wks }\end{array}$ & $\begin{array}{l}\text { Ligation of all aortic segmental } \\
\text { branches }\end{array}$ \\
\hline $\begin{array}{l}\text { Bi et al., } \\
2013\end{array}$ & Rabbit aorta & Peri-aortic elastase $(70 \mathrm{U}) \& 0.5-\mathrm{M} \mathrm{CaCl}_{2}$ & 20 mins & $\begin{array}{l}100 \% \text { at } 30 \\
\text { days }\end{array}$ & NR $(>50 \%)$ & $\begin{array}{l}\text { Ltd use for testing intracranial } \\
\text { devices }\end{array}$ \\
\hline $\begin{array}{l}\text { Fahed et } \\
\quad \text { al., } 2017\end{array}$ & $\begin{array}{l}\text { Rabbit CCA \& } \\
\text { subclavian } \\
\text { artery }\end{array}$ & $\begin{array}{l}\text { Intra-luminal elastase (100 U) \& dilation w/ } \\
\text { endovascular balloon }\end{array}$ & 20 mins & $\begin{array}{c}75 \% \text { at } 3 \\
\text { wks }\end{array}$ & $\begin{array}{l}54.6 \% \text { at } 3 \\
\text { wks }\end{array}$ & $\begin{array}{l}\text { Complex w/ both surgical \& } \\
\text { endovascular approaches; } \\
\text { Itd artery dilation }\end{array}$ \\
\hline $\begin{array}{l}\text { Hu et al., } \\
2017\end{array}$ & Rat aorta & $\begin{array}{l}\text { Modified Anidjar technique; divided infra- } \\
\text { renal aorta into } 4 \text { zones to specify aorta } \\
\text { puncture site for intra-aortic elastase }\end{array}$ & 30 mins & $\begin{array}{l}100 \% \text { at } 2 \\
\text { wks }\end{array}$ & $\begin{array}{r}\mathrm{NR}(>200 \% \\
\text { at } 4 \mathrm{wks})\end{array}$ & $\begin{array}{l}\text { High mortality rate (improved } \\
\text { from Anidjar model) }\end{array}$ \\
\hline $\begin{array}{l}\text { Lu et al., } \\
2017\end{array}$ & Mouse aorta & $\begin{array}{l}\text { Peri-aortic elastase }(0.3 \mathrm{U}) \mathrm{w} / \mathrm{BAPN} \\
\text { added to drinking water }(0.2 \%)\end{array}$ & 5 mins & $93 \%$ at $1 \mathrm{wk}$ & $\begin{array}{l}285.8 \% \text { at } 4 \\
\text { wks }\end{array}$ & $\begin{array}{l}\text { Aneurysm continues to spread } \\
\text { from exposed region }\end{array}$ \\
\hline $\begin{array}{l}\text { Tian et al., } \\
2018\end{array}$ & $\begin{array}{l}\text { Pig aorta } \\
\text { (thoracic) }\end{array}$ & Intra-adventitial elastase injections & NA & $\begin{array}{c}100 \% \text { at } 3 \\
\text { wks }\end{array}$ & NR $(\sim 60 \%)$ & $\begin{array}{l}\text { Invasive surgery; Itd artery } \\
\text { dilation }\end{array}$ \\
\hline $\begin{array}{l}\text { Current } \\
\text { model }\end{array}$ & Rabbit CCA & Peri-carotid elastase $(75 \mathrm{U}) \& 0.5-\mathrm{M} \mathrm{CaCl}_{2}$ & 20 mins & $\begin{array}{l}100 \% \text { at } 6 \\
\text { wks }\end{array}$ & $\begin{array}{c}88 \% \text { at } 6 \\
\text { wks }\end{array}$ & $\begin{array}{l}\text { Less dilation than some mod- } \\
\text { els; relatively simple arterial } \\
\text { configuration }\end{array}$ \\
\hline
\end{tabular}

$\mathrm{Ltd}=$ limited mins $=$ minutes; $\mathrm{NA}=$ not applicable; $\mathrm{NR}=$ not reported.

eral advantages over previously reported models. ${ }^{4}$ First, we achieved a $100 \%$ aneurysm formation rate using the combined agents (with no aneurysms formed in either control group), which is a greater success rate than the majority of published models. Our model's exposure time of 20 minutes also results in reduced anesthetic time for animals and thus lower morbidity. The topical application of elastase and $\mathrm{CaCl}_{2}$ does not require the use of a vessel cannulation system and fluoroscopy unit as is required for intra-arterial models. The use of a vessel cradle to bathe the CCA minimizes the exposure of surrounding tissues to the damaging effects of elastase and $\mathrm{CaCl}_{2}$ and allows the investigator to control the length of artery to be exposed to the solution. Finally, the peri-arterial application of elastase avoids exposing the enzyme to blood, which has been shown to inhibit elastase activity. ${ }^{18}$

\section{Conclusions}

We have shown that the peri-arterial incubation of the rabbit CCA with elastase and $\mathrm{CaCl}_{2}$ is sufficient to induce fusiform aneurysm formation over the course of 6 weeks. The mean aneurysmal dilation was $88 \%$, and aneurysm formation occurred in all rabbit CCAs treated with the combined agents. Aneurysms did not form in any rabbit CCAs incubated with elastase or $\mathrm{CaCl}_{2}$ individually. The proposed fusiform carotid aneurysm model is able to ac- commodate endovascular devices, simulates a more tortuous pathway than aortic models, and appears to be satisfactory for use in translational research.

\section{Acknowledgments}

We would like to thank Cheryl Hall for all of her assistance with both the creation of the aneurysms and the acquisition of the digital subtraction angiograms.

\section{References}

1. Altes TA, Cloft HJ, Short JG, DeGast A, Do HM, Helm GA, et al: 1999 ARRS Executive Council Award. Creation of saccular aneurysms in the rabbit: a model suitable for testing endovascular devices. AJR Am J Roentgenol 174:349-354, 2000

2. Anidjar S, Salzmann JL, Gentric D, Lagneau P, Camilleri JP, Michel JB: Elastase-induced experimental aneurysms in rats. Circulation 82:973-981, 1990

3. Anson JA, Lawton MT, Spetzler RF: Characteristics and surgical treatment of dolichoectatic and fusiform aneurysms. J Neurosurg 84:185-193, 1996

4. Bi Y, Zhong H, Xu K, Zhang Z, Qi X, Xia Y, et al: Development of a novel rabbit model of abdominal aortic aneurysm via a combination of periaortic calcium chloride and elastase incubation. PLoS One 8:e68476, 2013

5. Chalouhi N, Hoh BL, Hasan D: Review of cerebral aneurysm formation, growth, and rupture. Stroke 44:3613-3622, 2013 
6. Dai D, Ding YH, Danielson MA, Kadirvel R, Lewis DA, Cloft HJ, et al: Histopathologic and immunohistochemical comparison of human, rabbit, and swine aneurysms embolized with platinum coils. AJNR Am J Neuroradiol 26:2560-2568, 2005

7. Davis FM, Rateri DL, Daugherty A: Mechanisms of aortic aneurysm formation: translating preclinical studies into clinical therapies. Heart 100:1498-1505, 2014

8. Ding Y, Dai D, Kadirvel R, Lewis DA, Kallmes DF: Fiveyear follow-up in elastase-induced aneurysms in rabbits. AJNR Am J Neuroradiol 31:1236-1239, 2010

9. Fahed R, Darsaut TE, Salazkin I, Gentric JC, Mazighi M, Raymond J: Testing stenting and flow diversion using a surgical elastase-induced complex fusiform aneurysm model. AJNR Am J Neuroradiol 38:317-322, 2017

10. Findlay JM, Hao C, Emery D: Non-atherosclerotic fusiform cerebral aneurysms. Can J Neurol Sci 29:41-48, 2002

11. Flemming KD, Wiebers DO, Brown RD Jr, Link MJ, Nakatomi H, Huston J III, et al: Prospective risk of hemorrhage in patients with vertebrobasilar nonsaccular intracranial aneurysm. J Neurosurg 101:82-87, 2004

12. Gertz SD, Kurgan A, Eisenberg D: Aneurysm of the rabbit common carotid artery induced by periarterial application of calcium chloride in vivo. J Clin Invest 81:649-656, 1988

13. Hu G, Dong Z, Fu W: A novel modification of the murine elastase infusion model of abdominal aortic aneurysm formation. Ann Vasc Surg 42:246-253, 2017

14. Isenburg JC, Simionescu DT, Starcher BC, Vyavahare NR: Elastin stabilization for treatment of abdominal aortic aneurysms. Circulation 115:1729-1737, 2007

15. Lu G, Su G, Davis JP, Schaheen B, Downs E, Roy RJ, et al: A novel chronic advanced stage abdominal aortic aneurysm murine model. J Vasc Surg 66:232-242, 242.e1-242.e4, 2017

16. Nakatomi H, Segawa H, Kurata A, Shiokawa Y, Nagata K, Kamiyama H, et al: Clinicopathological study of intracranial fusiform and dolichoectatic aneurysms: insight on the mechanism of growth. Stroke 31:896-900, 2000
17. Roussi J, André P, Samama M, Pignaud G, Bonneau M, Laporte A, et al: Platelet functions and haemostasis parameters in pigs: absence of side effects of a procedure of general anaesthesia. Thromb Res 81:297-305, 1996

18. Schulz H, Mohr M, Meyer M: Elastase and papain inhibition by serum of mammals. Scand J Clin Lab Invest 49:381388,1989

19. Tanaka A, Hasegawa T, Chen Z, Okita Y, Okada K: A novel rat model of abdominal aortic aneurysm using a combination of intraluminal elastase infusion and extraluminal calcium chloride exposure. J Vasc Surg 50:1423-1432, 2009

20. Tian Y, Zhang W, Sun J, Zhai H, Yu Y, Qi X, et al: A reproducible swine model of proximal descending thoracic aortic aneurysm created with intra-adventitial application of elastase. J Vasc Surg 67:300-308, 308.e1-308.e2, 2018

\section{Disclosures}

The authors report no conflict of interest concerning the materials or methods used in this study or the findings specified in this paper.

\section{Author Contributions}

Conception and design: Mitha, Avery, Alaqeel, Wong, Eesa. Acquisition of data: Avery, Alaqeel, Bromley, Chen. Analysis and interpretation of data: Mitha, Avery, Bromley, Chen. Drafting the article: Avery. Critically revising the article: all authors. Reviewed submitted version of manuscript: all authors. Statistical analysis: Avery. Administrative/technical/material support: Mitha, Bromley, Chen, Eesa. Study supervision: Mitha.

\section{Correspondence}

Alim P. Mitha: Foothills Medical Centre, Calgary, AB, Canada. amitha@ucalgary.ca. 